\title{
Melhoramento genético na apicultura comercial para produção da própolis ${ }^{1}$
}

\author{
Genetic improvement in the commercial Bbeekeeping in production of propolis
}

\author{
MARTINEZ, Omar Arvey ${ }^{2 *}$; SOARES, Ademilson Espencer Egea ${ }^{3}$
}

\author{
${ }^{1}$ Revisão apresentada no Congresso Brasileiro de Zootecnia (ZOOTEC 2011). \\ ${ }^{2}$ Universidade de São Paulo; Faculdade de Medicina de Ribeirão Preto; Departamento de Genética, \\ Ribeirão Preto, São Paulo, Brasil \\ ${ }^{3}$ Universidade de São Paulo; Faculdade de Medicina de Ribeirão Preto; Departamento de Genética, \\ Ribeirão Preto, São Paulo, Brasil \\ *Endereço para correspondência: omarapis@yahoo.com.br
}

\section{RESUMO}

O melhoramento genético de abelhas Apis mellifera é uma ferramenta essencial e de caráter obrigatório para o sucesso e desenvolvimento da indústria apícola. Práticas de manejo, troca das rainhas e inseminação instrumental constituem os pilares fundamentais de um programa que vise o aumento de determinada característica quantitativamente. A diversidade de climas no Brasil, junto com a possibilidade de direcionar a produção de diferentes produtos, fazem deste um país com oportunidades no campo internacional da apicultura. Programas de melhoramento genético, em grande escala, precisam ser feitos a partir de populações em massa, ou seja, um programa de melhoramento deverá iniciar-se a partir de um grande número de colmeias para serem selecionadas, com a finalidade de desenvolver e estruturar um programa de melhoramento genético que tenha como objetivo incrementar os níveis de produção e assim aumentar as médias de produção por colmeia em geral. Algumas características podem ser utilizadas para selecionar as colmeias, como: produção de própolis; a qualidade da própolis coletada; comportamento higiênico; taxa de infestação de varroa e incidência de Nosema. Isso garante a seleção das melhores colmeias como base do programa de melhoramento genético. Adicionalmente, padronização de práticas de manejo, troca constante de rainhas, produção de zangões, avaliação contínua da produção e a inseminação instrumental são práticas constantes nos apiários do programa de melhoramento em própolis.

Palavras chave: comportamento higiênico, inseminação instrumental, produção de rainhas, seleção.

\section{SUMMARY}

The genetic improvement programs of honeybees Apis mellifera are an essential and important tool for the success and development of the beekeeping industry. Hence, the use of other tools such as instrumental insemination, management practices, and exchange of queens are necessary to allow production increase. The diversity of climates in Brazil along with the ease of producing different products makes Brazil a country with great opportunities in the field of international beekeeping. Breeding programs on a large scale need to be made from mass populations, in other words, a breeding program should start from a large number of hives to be selected. With the purpose of developing and designing a breeding program that aims to increase production levels and thus increase the average yield per colony in general. Some features may be used to select the hives as propolis production, the quality of propolis collected, as well as some other features: hygienic behavior, rate of varroa infestation and incidence of Nosema. This ensures the best selection of hives as the basis of genetic improvement program. Additionally, standardization of management practices, constant exchange of queens, production of drones, continuous evaluation of production and insemination practices are contained in the apiaries of the breeding program in propolis.

Keywords: hygienic behavior, insemination, production of queens, selection.. 


\section{INTRODUÇÃOO}

A produção animal resulta da ação conjunta das forças de origem genética e do ambiente. Níveis altos de produção só podem ser alcançados pelo melhoramento simultâneo da composição genética dos animais e das condições ambientais. A parte genética é a base para o estabelecimento de programas de melhoramento e o fator que limita a capacidade de resposta dos animais aos processos seletivos. É indispensável compatibilizar a parte genética com as condições ambientais, pois os níveis de produção são aspectos dependentes da utilização racional dessas duas forças (CAMPOS, 2008).

O melhoramento genético de abelhas Apis mellifera é uma ferramenta essencial e de caráter obrigatório para o sucesso e desenvolvimento da indústria apícola. Práticas de manejo, troca das rainhas e inseminação instrumental se constituem pilares fundamentais de um programa que vise $o$ aumento de determinada característica quantitativamente. A diversidade de climas, junto com a possibilidade de direcionar a produção para outros ramos, fazem do Brasil um país promissor no campo internacional da apicultura.

A apicultura mundial tem evoluído, recentemente, no sentido de incrementar os níveis de produção e padronizar seus processos. Os produtos apícolas têm alcançado um importante mercado mundial e, hoje em dia, sob o conceito de produto orgânico, têm atraído um seleto grupo de consumidores. Além disso, seu consumo expande-se ano após ano, o que gera oportunidade para que empresas do segmento se especializem na produção desses produtos. Esse crescimento contínuo exige uma adoção e desenvolvimento de técnicas de manejo, por parte dos apicultores, que permitam realizar e projetar um tipo de apicultura que desenvolva a máxima produção por colônia.

No mercado mundial apícola, podemos encontrar uma gama de produtos da colmeia, entre os quais se destacam: mel, pólen, própolis, geleia real, apitoxina, entre outros. Cada um desses elementos possui, em particular, um efeito tanto genético, como fenotípico, que expressam o potencial de cada uma das colmeias componentes dum apiário.

\section{CENÁRIO APÍCOLA NO BRASIL}

Um breve panorama da apicultura, no Brasil, revela momentos marcantes no cenário agrário. Transformações significativas ocorreram desde sua implantação, em 1839, quando foram introduzidas as abelhas melíferas de origem europeia na região Sudeste, o que causou impacto tecnológico, biológico, econômico e social. Posteriormente, na década de 1950, um pesquisador brasileiro, Warwick Estevam Kerr, deu início ao que poderíamos reconhecer como os primeiros trabalhos brasileiros sobre melhoramento das abelhas Apis mellifera.

Devido à baixa produtividade das abelhas europeias (Apis mellifera ligustica, Apis mellifera carnica, Apis mellifera caucasica e Apis mellifera mellifera) no Brasil, foram importadas linhagens mais produtivas e adaptáveis ao clima tropical. Em 1956, foram introduzidas no Brasil 33 rainhas africanas (Apis mellifera scutellata) para iniciar um programa de seleção e melhoramento genético. Em 1957, enxamearam 26 dessas colônias, de modo a originar o processo de 
Africanização (GONÇALVES, 1974; GONÇALVES, 1992), no Brasil e na América.

Hoje, as abelhas africanizadas são responsáveis pelo desenvolvimento apícola do país. Possuem tolerância a várias pragas e doenças que assolam a atividade em todo o mundo, de modo que não têm acarretado impacto econômico no Brasil. O país também conquistou posição de destaque no mercado externo e está na lista dos maiores exportadores.

Comercialmente, a própolis tem ocupado lugar de destaque no mercado nacional e internacional de produtos apícolas. Sua inserção se deve, essencialmente, às constatações das inúmeras atividades biológicas atribuídas aos seus constituintes químicos. Como consequência, observou-se aumento do valor agregado ao produto.

O setor apícola brasileiro apresenta tendência ao crescimento, o que motiva os apicultores a aumentarem suas produções. Portanto, é de grande importância a profissionalização da apicultura no Brasil para responder aos níveis e padrões produtivos e de qualidade, exigidos nos países importadores de mel e outros produtos apícolas.

\section{ASPECTOS BIOLÓGICOS REPRODUTIVOS}

As abelhas Apis mellifera são insetos sociais, habitantes de colônias organizadas. Dividem-se em castas e possuem funções bem definidas, executadas em prol da sobrevivência e manutenção do enxame. Nas abelhas melíferas, a rainha é quase duas vezes maior que as operárias e pode viver por períodos de até dois anos. Sua única função biológica é a postura de ovos, enquanto do ponto de vista social, é responsável pela harmonia, estabilidade social e coordenação dos trabalhos da colônia. A determinação do sexo é dada pelo fato de tais insetos serem haploides ou diploides, assim embriões diploides se desenvolvem de ovócitos fertilizados, tornam-se fêmeas, e os embriões oriundos de ovócitos não fertilizados, tornam-se machos. $\mathrm{O}$ fato de determinada fêmea desenvolver-se ou não em uma forma reprodutiva (rainha), depende de sua alimentação durante o desenvolvimento (SNUSTAD \& SIMMONS, 2001).

No momento em que as pessoas começaram a criar abelhas, desfrutaram dos benefícios de ter uma população grande e variável de insetos com a qual trabalhar. Isso facilitou a descoberta, da parte dos criadores, de que aquelas respondiam bem à seleção. Em parte, isso se deve ao fato dos seres humanos apenas estarem no início do trabalho de modificação das abelhas, através da seleção e produção controlada de rainhas. Desenvolver o costume de trocar as rainhas anualmente é um passo essencial a ser tomado na implementação de um programa de melhoramento produtivo. Dessa forma, podemos trocar em um pequeno intervalo de tempo a genética de cada colmeia. Aprender e aperfeiçoar as técnicas da criação de rainhas é tarefa de muitos apicultores, os quais devem se especializar em fornecer rainhas a outros profissionais da apicultura.

A troca de rainhas, por exemplo, traz muitas vantagens para os produtores, fato que permite um seguimento mais preciso das colmeias e as respostas à seleção são muito mais rápidas. A troca anual é uma prática pouco estabelecida pelo apicultor devido, em parte, ao tipo de manejo que é realizado nos apiários de produção e, em parte, ao desconhecimento das vantagens 
existentes na alternância contínua das rainhas. Quando é executada, é comum observar-se um aumento na produção dos apiários, bem como a manutenção da força e homogeneidade das colônias durante a maior parte do ano.

Além disso, em regiões tropicais, a rainha realiza postura o ano inteiro, de forma a intensificar seu desgaste natural, o que torna necessário cambiála por nova rainha ao final do período produtivo. Assim, a troca de rainhas é muito importante em um programa de melhoramento, devido ao fato das colônias com rainhas jovens serem mais produtivas que colônias com rainhas velhas (KOSTARELOUDEMIANIDOU et al., 1995).

\section{MELHORAMENTO GENÉTICO}

Para acelerar o melhoramento genético, alguns autores sugeriram a substituição de $25 \%$ das rainhas com os menores índices de produção, o que acarretou, na prática, um aumento significativo de até $20 \%$. Ainda, a substituição de mais de $25 \%$ das rainhas leva a um aumento na média da população. Propõe-se que, para tornar um programa de seleção eficiente, deve ser feito, no mínimo, a partir das 24 melhores colônias que o apicultor possuir, das quais 12 serão usadas para produção de rainhas e as outras 12 para produzir grande número de zangões de qualidade genética. Adicionalmente, a seleção dos machos deve ser feita a partir do desempenho de suas irmãs.

É importante que o apicultor tenha consciência de que as abelhas africanizadas são um poli-híbrido, formado originalmente por abelhas africanas, normalmente mais resistentes às diferentes doenças, mas também por abelhas europeias diversas que, normalmente, são menos resistentes. Dessa forma, espera-se que um percentual dessas colmeias seja também suscetível. Essas últimas poderão ser eliminadas, naturalmente, de forma lenta, no caso da ocorrência de novos patógenos ou de linhagens mais virulentas. Por outro lado, podem ser eliminadas de forma mais acelerada pela ação do próprio apicultor, ao eliminar as rainhas de colmeias com sintomas de doenças, o que implica uma substituição por rainhas provenientes de colmeias sem sintomas e mais produtivas (MESSAGE, 2010).

O melhoramento genético de abelhas apresenta algumas diferenças em relação a outras espécies animais. Estimativas como herdabilidade, semelhança entre parentes e outras, são difíceis de serem obtidas, se for considerado que as colônias apresentam uma estrutura genética interna que dificulta tal procedimento.

Em um programa de melhoramento genético de abelhas melíferas, é necessário o uso de ferramentas como a inseminação instrumental que permite aumentar os níveis produtivos sem usar os métodos quantitativos tradicionais. Essa ferramenta é essencial tanto para o pesquisador, que precisa de cruzamentos específicos, quanto para o apicultor envolvido em um programa de melhoramento produtivo. As diferentes contribuições de especialistas e cientistas, nos últimos 60 anos, possibilitaram o aperfeiçoamento da técnica.

A habilidade de controlar os acasalamentos permite a seleção, desenvolvimento e manutenção de características desejadas. Dessa maneira, a indústria apícola se beneficiaria, caso desejasse manter as linhagens "resistentes" que estão em desenvolvimento, o que justifica a incorporação dessa tecnologia aos 
programas comerciais de criação de abelhas (COBEY \& SCHLEY, 2002).

Naturalmente, a rainha virgem se acasala no ar, nunca no interior da colmeia. Essa independência de acasalamento das rainhas desencorajou muitos apicultores a criarem abelhas como os demais animais domésticos; por essa razão, o controle dos acasalamentos das rainhas virgens foi um grande anseio dos apicultores por mais de um século antes de ser alcançado. A inseminação mostrou-se um método que controla e resolve os tipos de cruzamentos (LAIDLAW, 2000).

Hoje, as melhorias na técnica e no desenho dos equipamentos possibilitaram que o procedimento se tornasse mais fácil de aprender e de aplicar. Assim, é possível conseguir, das rainhas inseminadas, altas taxas de sucesso e níveis de desempenho similares aos das rainhas fecundadas naturalmente. Diferenças entre rainhas acasaladas naturalmente e rainhas inseminadas devem-se principalmente à quantidade de sêmen utilizado; à idade das rainhas; aos métodos de introdução, aos cuidados pré e pós-inseminação (COBEY, 2007).

A técnica tem a flexibilidade necessária para realizar muitos tipos de acasalamentos controlados. Porém, uns dos mais utilizados é a inseminação de rainhas com uma mistura uniforme de espermatozoides. Entre outras possibilidades, essa técnica pode ser usada para manter a heterogeneidade genética num programa de melhoramento ou para produzir inseminações uniformes, mais heterogêneas geneticamente, em um grupo de rainhas. Essas inseminações incluem espermatozoides, geneticamente diversos, mas que são uniformes, porque o sêmen para cada inseminação é coletado aleatoriamente de um grupo grande de machos $\mathrm{e}$ misturado em um pool gênico.

Alguns complementos importantes a essa técnica na apicultura especializada e que geralmente são ignorados principalmente por iniciantes são: criação e maturação dos machos e das rainhas; cuidados na pré e pósinseminação das rainhas; e a introdução adequada das rainhas inseminadas. $\mathrm{O}$ êxito depende de um cuidadoso planejamento de todos esses processos dentro de um programa (COBEY, 2007). A produção de zangões é uma prática fundamental em um programa de inseminação, já que garante a qualidade e a quantidade de zangões imprescindíveis no processo (FERT, 2008).

Os fundamentos da seleção baseiam-se nas disciplinas matemáticas da genética quantitativa e de populações. O ponto de partida básico para compreender a seleção é o conceito do fenótipo (as características de um animal que podem ser observadas), o qual resulta das influências da genética do animal, do ambiente onde o animal se encontra e das interações entre esses dois fatores. Esse conceito pode ser estendido à populações de animais. A variação de genótipos resultantes da genética pode ser subdividida em vários tipos diferentes de eventos genéticos. A variância devido a eventos genéticos aditivos é especialmente importante. A variância aditiva é a causa genética principal da semelhança entre parentes e, portanto, o determinante principal de como facilmente uma população pode ser melhorada pela seleção (RINDERER, 1986).

A medida acurada das características é essencial para o sucesso de um programa de seleção. A via mais importante para incrementar a acurácia é tomar medidas nas abelhas que se encontram em um ambiente comum e 
com histórias de manejo semelhante. $\mathrm{O}$ grupo de colônias deve partir de um ponto comum no tempo para registro. No futuro, estas serão avaliadas, quando o apiário ou outras condições permitam uma expressão completa das capacidades das colmeias. Por exemplo, a avaliação da produção de mel deve ser feita durante condições de fluxo de néctar que, são condições típicas nas quais se espera que o estoque melhore e demonstre seu melhor desempenho. Medidas mais precisas ou medidas repetidas, como método para aumentar a precisão, podem melhorar a acurácia (RINDERER, 1986).

A natureza da apicultura requer, com frequência, a avaliação de características no campo. Sem dúvida, as condições de campo aumentam a variância ambiental. A menos que se dê atenção à redução dessa variação, as medidas podem ser insuficientemente precisas e a seleção pode não produzir nenhuma melhora significativa.

De fato, a herdabilidade pode ser reduzida substancialmente (RINDERER, 1986). A herdabilidade, $h^{2}$, é uma das mais importantes propriedades de uma característica quantitativa. Representa o grau de relação da variância genética aditiva com $\mathrm{o}$ total ou variância fenotípica, isto é, a proporção da variação total que é atribuível a efeitos aditivos e os efeitos médios de todos os genes que afetam uma característica. O tamanho de $h^{2}$ indica a similaridade de organismos relacionados. Sua função mais importante, no estudo de características quantitativas, é que ela pode predizer quão confiável é o valor fenotípico como guia para o valor genético real do indivíduo.

Um manejo padrão para todas as colmeias é uma medida importante para reduzir a variabilidade ambiental nos testes de campo. O uso de rainhas da mesma idade, introduzidas em populações de abelhas de igual tamanho, quantidades iguais de material, suplementos alimentícios, tratamentos químicos etc., é útil, a depender do que se esteja em avaliação. A hora e as condições ambientais do dia também são fatores importantes (RINDERER, 1986). Existem vários tipos de seleção que podem ser aplicados ao melhoramento de abelhas, porém, quatro estratégias de seleção, também aplicáveis às populações abertas com bons ganhos genéticos, têm dado os melhores resultados em populações fechadas.. Estas são: 1. Seleção dentro da família, na qual se escolhe a rainha filha com o valor fenotípico mais alto de cada rainha matriz; 2. Seleção em massa, as novas rainhas matrizes são escolhidas independentes de relações familiares; 3 . Seleção em massa combinada com seleção para alta viabilidade da cria; 4 . Seleção ao acaso para as novas matrizes (OMHOLT \& ÅDNØY, 1994). A seleção em massa é o primeiro método utilizado em populações que não sofreram nenhum melhoramento. Em abelhas, resulta em bons ganhos iniciais, principalmente, em híbridos africanizados.

\section{A PRÓPOLIS}

A própolis é um produto elaborado pelas abelhas com suas secreções, resinas de árvores, cera, pólen e fragmentos de vegetais. Sua composição química depende, portanto, da flora da região onde é produzida e da época do ano em que é coletada. A própolis do arbusto alecrim-do-campo (Baccharis dracunculifolia), conhecida também como própolis verde, é produzida do broto dessa planta, que é endêmica em várias regiões do Brasil. Entretanto, por razões ainda 
desconhecidas, essa própolis é produzida, fundamentalmente, no sul, leste, centro e zona da mata de Minas Gerais, leste de São Paulo, norte do Paraná e em regiões serranas do Espírito Santo e Rio de Janeiro (BASTOS, 2001).

A própolis de alecrim-do-campo constitui, portanto, um produto tipicamente brasileiro e, devido ao fato de ser altamente eficaz no combate a uma série de micro-organismos, é altamente valorizada no mercado internacional, no qual, atualmente, o Japão é o principal importador desse nosso produto nacional. Muitas variáveis podem influenciar a qualidade e a quantidade de própolis produzido em cada colmeia, entre elas podemos citar: luminosidade, pluviosidade, tipo de coletor utilizado, alimentação energética e proteica. Finalmente, a genética utilizada nos apiários destinados à produção de própolis verde também deve ser considerada, pois, é uma característica quantitativa que pode ser facilmente utilizada num programa de melhoramento genético (LIMA, 2006).

Em um programa de melhoramento genético para a produção de própolis, as colmeias são selecionadas, principalmente, pelos seus níveis de produção e qualidade da própolis coletada. Porém, nestas colmeias, e segundo o objetivo e estruturação do programa, são igualmente observadas diferentes características como: comportamento higiênico, incidências de doenças (varroatose, nosemose), como também em alguns casos medidas morfométricas.

O ácaro Varroa destructor é um ectoparasita de larvas, pupas e adultos das abelhas do gênero Apis e é uma das pragas que mais causam problemas à apicultura comercial em grande parte do mundo. A infestação com varroa ocasiona, além de deformações em diversos órgãos como asas, pernas, abdômen e tórax, causa redução da longevidade, tamanho, peso, atividade de coleta e resistência a outras doenças. As larvas muito infestadas morrem.

A varroatose é causada por esse ácaro, e as abelhas africanizadas apresentam alta tolerância. Esse fato tem evitado o uso de pesticidas ao longo dos anos na apicultura com abelhas africanizadas, porém é comum observar, nos últimos anos, altas taxas de infestação em alguns apiários com essas abelhas. Levantamentos realizados, no sudeste do Brasil, têm demonstrado uma maior taxa reprodutiva desse ácaro nos últimos anos, mas também se observou que existe uma variabilidade entre colônias, o que possibilita a seleção (MESSAGE, 2010). Essa característica de infestação de abelhas africanizadas é, atualmente, utilizada nos programas de seleção e melhoramento genético.

A Nosemose é causada pelo desenvolvimento de um de dois microsporídeos - Nosema apis ou Nosema ceranae - nas células da mucosa do intestino médio de abelhas adultas: operárias, zangões e rainhas, enquanto os ovos, ninfas e larvas não são atacados (BAILEY \& BALL, 1991). Com a evolução das técnicas de identificação de patógenos, que agora utilizam métodos moleculares, tornouse possível identificar a presença de uma nova espécie do microsporídio, inicialmente, detectado em abelhas Apis cerana e, logo em seguida, em abelhas europeias, o qual foi denominado de Nosema ceranae.

No Brasil, a doença causada pela Nosema apis praticamente desapareceu com o avanço da africanização das abelhas. No entanto, em 2006, foram observados a presença de esporos de Nosema spp, os quais foram devidamente identificados como sendo 
a Nosema ceranae (MESSAGE, 2010). Atualmente, com a problemática do desaparecimento das abelhas, essa doença é foco de diversas pesquisas ao nível internacional e nacional.

Segundo os interesses, com as características utilizadas para a seleção do material parental se determinam as linhas maternas e as linhas paternas para realizar os determinados cruzamentos. A partir desse grupo inicial de colmeias selecionadas, serão criadas e estabelecidas as linhas genéticas que serão testadas em campo. Ao longo do tempo, é possível que o apicultor adicione novos parâmetros de seleção, os quais serão determinados segundo os objetivos particulares do programa de melhoramento genético. Adicionalmente, algumas práticas de manejo são estabelecidas, como: troca anual de rainhas; marcação e seguimento das rainhas dos apiários; duas ou três avaliações de comportamento higiênico ao longo do ano, além de realizar e desenvolver o mesmo tipo de manejo de forma similar em todos os apiários que formam ou fazem parte do programa de melhoramento a ser desenvolvido.

Inicialmente, espera-se que o avanço genético nos primeiros anos seja facilmente observado nas médias de produção das colmeias pelo fato dos apicultores não trocarem as rainhas constantemente.

A produção de própolis iniciou-se nas últimas décadas, por isso, um programa de melhoramento que vise o aumento nas médias de produção dessa característica e favoreça o mercado nacional, de modo a gerar mais ingressos aos apicultores e explorar ao máximo os apiários de produção, tornase muito necessário.

\section{AGRADECIMENTOS}

Os autores agradecem ao Conselho Nacional de Desenvolvimento Científico e Tecnológico $(\mathrm{CNPq})$ e à Coordenação de Aperfeiçoamento de Pessoal de Nivel Superior (CAPES) como também a todos os apicultores que fazem parte deste trabalho.

\section{REFERÊNCIAS}

\author{
BAILEY, L.; BALL, B.V. Honey bee \\ pathology. 2nd Edition. London: \\ Academic Press, 1991. 208p.
}

\section{BASTOS, E.M.A.F. Origem botânica e indicadores de qualidade da "própolis verde" produzida no Estado de Minas} Gerais. 2001. 137p. Tese (Doutorado) Universidade de São Paulo, Faculdade de Filosofia, Ciências e Letras, Ribeirão Preto.

\section{CAMPOS, J.C.P. Melhoramento genético aplicado à produção animal. Belo Horizonte, MG: FEPMVZ, 2008. $617 \mathrm{p}$.}

COBEY, S. Comparison studies of instrumentally inseminated and naturally mated honey bee queens and factors affecting their performance. Apidologie, v.38, p.390-410, 2007.

COBEY, S., SCHLEY, P. Innovations in instrumental insemination. The compact, versatile right and left handed Schley model II instrument. American Bee Journal, v.142, n.6, p.433-435, 2002.

FERT, G. El rol de la crianza de zánganos en el manejo de la cría de reinas para mejorar la calidad de las reinas. In: WORLD SYMPOSIUM OF QUEEN BEES AND ARTIFICIAL

INSEMINATION, 2, 2008, Nuevo

Vallarta, Mexico. Anais... Nuevo Vallarta, Nayarit. Mexico, 2008. p.101. 
GONÇALVES, L.S. The introduction of the African Bees (Apis mellifera scutellata) into Brazil and some comments on their spread in South America. American Bee Journal, v.114, n.11, p.414-419, 1974.

GONÇALVES, L.S. Africanização das abelhas nas Américas, impactos e perspectivas de aproveitamento do material genético.In: ENCONTRO BRASILEIRO DE ABELHAS E OUTROS INSETOS SOCIAIS. HOMENAGEM AOS 70 ANOS DE WARWICK ESTEVAM KERR, 1992, São Paulo. Anais... São Paulo: Unesp, 1992. p.126-134.

KOSTARELOU-DAMIANIDOU, M.; THRASYVOULOU, A.; TSELIOS, D.; BLADENOPOULOS, K.. Brood and honey production of honeybee colonies requeened at various frequencies.

Journal Apicultural Research, v.34, p.9-14, 1995.

\section{LAIDLAW, H.H. Production of} queens and package bees. The hive and the honeybee. Chelsea, MI: Bookcrafters, 2000. p.235-267.
LIMA, M.G. A produção de própolis no Brasil. São Sebastião da Gama, SP: Impressos São Sebastião, 2006. 120p.

MESSAGE, D. Principais problemas sanitários em apiários do Brasil. In: CONGRESSO ÍBEROAMERICANO DE APICULTURA, 10, 2010,. Natal, RN. Anais... Natal, RN, 2010.

OMHOLT, S.W.; ÅDNØY, T. Effects of various breeding strategies on diploid drone frequency and quantitative traits in a honey bee population.

Theorethical and Applied Genetics, v.89, p.687-692, 1994.

RINDERER, T.E. Selection in Bee genetics and breeding. Academic Press, 1986. p.305-321.

SNUSTAD, D.P.; SIMMONS, M.J. Fundamentos de genética: a base cromossômica do mendelismo. 2.ed. Rio de Janeiro. Guanabara Koogan, 2001. 114p.

Data de recebimento: 10/11/2011

Data de aprovação: 05/11/2012 